\title{
Structural Performance of Single Axial Expanded Dome under Seismic Loading
}

\author{
Parvathy K.T \\ Department of Civil Engineering \\ Sree Narayana Gurukulam College of Engineering \\ Ernakulam, India
}

\author{
Dr. Usha S \\ Department of Civil Engineering \\ Sree Narayana Gurukulam College of Engineering \\ Ernakulam, India
}

\begin{abstract}
Dome structures are the most preferred for large spanned structures. Dome structures are lightweight and elegant structures that provide economical solutions for covering large areas with their splendid aesthetic appearance. Dome covers the maximum volume with the minimum material volumes without interrupting columns in the middle space. In this study steel domes with various rise to span ratio having same diameter were modeled and analyzed statically and dynamically. The static and dynamic analysis of domes under seismic loading by single axial expansion were performed .The maximum lateral force acting in the structure under seismic loading are obtained through the analysis.
\end{abstract}

Keywords - Single axial expansion; seismic loading; Varying rise to span ratios

\section{INTRODUCTION}

Steel domes are one of the most efficient shapes in the world to cover large spans. Dome structures are lightweight and elegant structures that provide economical solutions for covering large areas with their splendid aesthetic appearance. Dome covers the maximum volume such as exhibition halls, stadium and concert halls with efficient shapes using minimum material. In recent decades, there has been an increasing demand for super long span space structures; they can be highly efficient, beautiful and economically feasible. Large-span spatial structures are always landmarks in cities. At present, predicting the potential damage to large-span spatial structures subjected to seismic loading is a significant issue for civil engineers. Elucidating the failure modes and failure mechanisms is important to effectively minimize the damage to the structures.

\section{OBJECTIVES}

- To model the domes with same diameter and varying rise to span ratio using single axial expansion

- To evaluate the structural performance of domes under varying expansion aspect ratio.

- To study the static and dynamic analysis of domes under seismic loading by single axial expansion.

\section{SUMMARY OF LITERATURE REVIEW}

Steel domes are efficiently used to cover large span structures. Dome structures are lightweight and elegant structures that provide economical solutions for covering large areas with their splendid aesthetic appearance. Studies were mainly carried out on the modelling of domes with same diameter and varying rise to span ratio using dual manipulation concept [1]. Static loading performance of domes under single axial expansion and dual axial expansions were mainly carried out [2]. Structural behavior of domes was analyzed by conducting parametric study on aspect ratio, different span ratio etc. [3]. Study of structural behavior of domes under dynamic loading was also conducted [4].

\section{NUMERICAL ANALYSIS}

The static and dynamic analysis of domes under seismic loading by single axial expansion was performed using ANSYS 16.1 WORKBENCH, a finite element software for mathematical modelling and analysis.

\section{A. Material properties}

The material properties of the steel domes are tabulated in Table 1.

TABLE I. MATERIAL PROPERTIES

\begin{tabular}{|c|c|}
\hline Element Type & Material Property \\
\hline Beam 188 & Young's modulus $=2.1$ X10 $10^{5} \mathrm{MPa}$ \\
& Poisson's ratio $=0.3$ \\
& Yield strength $=235 \mathrm{MPa}$ \\
\hline
\end{tabular}

\section{B. Base model}

Numerical modelling of steel domes with same diameter and varying rise span ratio were done using ANSYS 16.1 WORKBENCH. The structural performance of domes (buckling) were done under varying expansion aspect ratio after the modelling of domes by using single axial expansion. Four models of Keiwitt- 8 single layer reticulated domes were done with different spans $(40 \mathrm{~m}, 44 \mathrm{~m}, 48 \mathrm{~m} \& 60 \mathrm{~m})$ by varying rise to span ratios as $1 / 5,2 / 11,1 / 6,2 / 15$. The input data for material properties are shown in Table 1. 


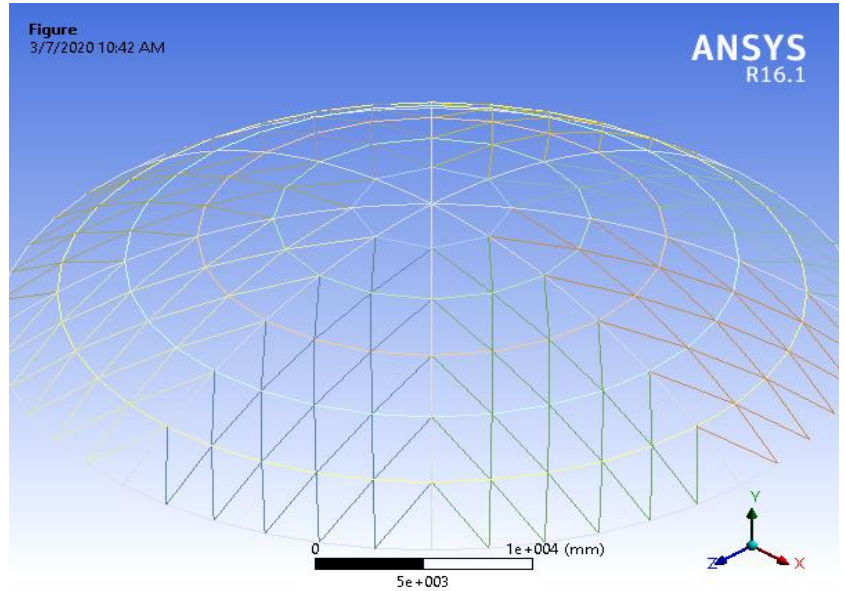

Fig. 1. Dome with span $40 \mathrm{~m}$ and rise to span ratio $(\mathrm{f} / \mathrm{L})=1 / 5$

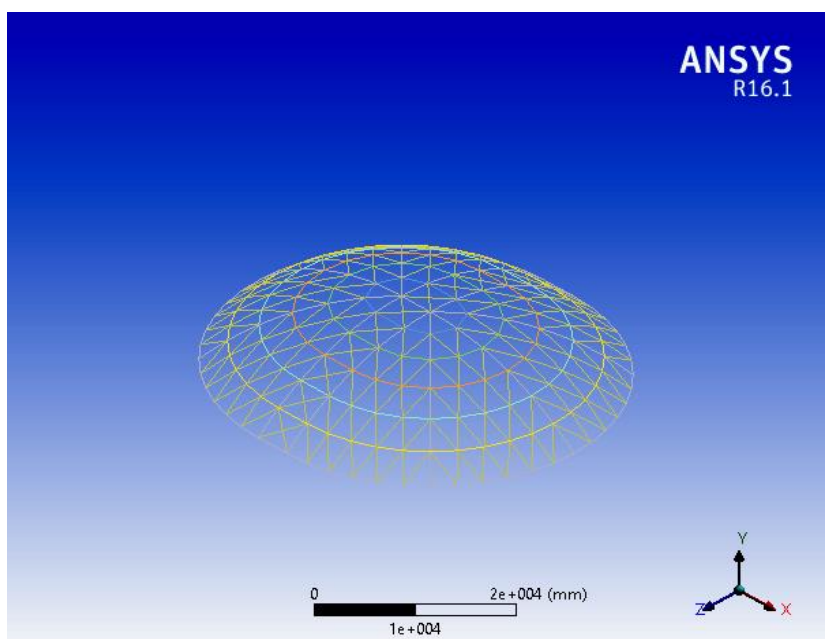

Fig. 2.Dome with span $44 \mathrm{~m}$ and rise to span ratio $(\mathrm{f} / \mathrm{L})=2 / 11$

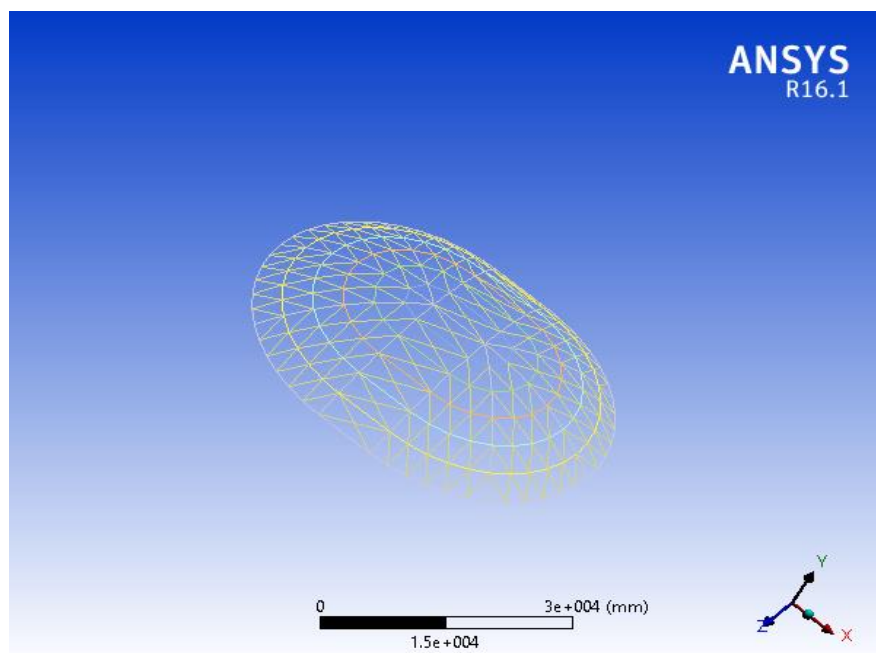

Fig. 3. Dome with span $48 \mathrm{~m}$ and rise to span ratio $(\mathrm{f} / \mathrm{L})=1 / 6$

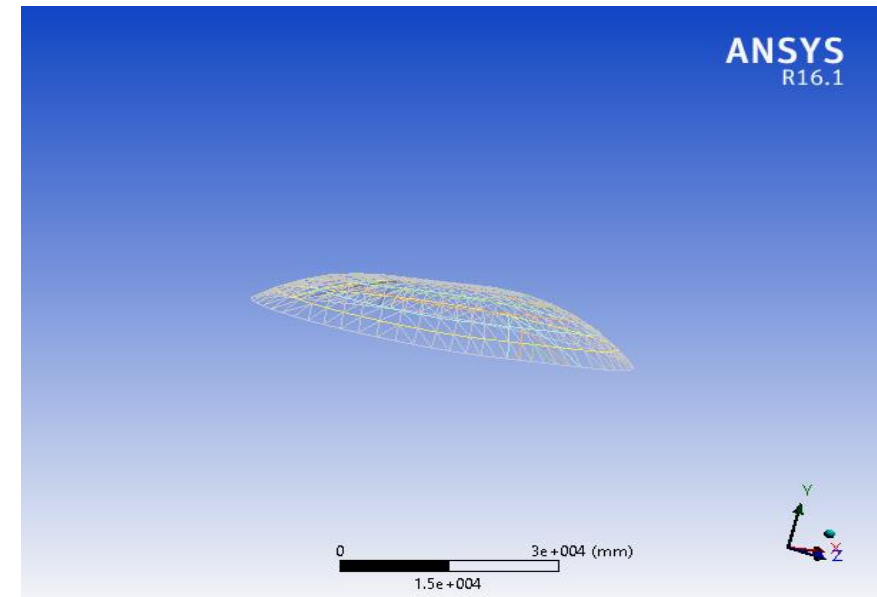

Fig. 4. Dome with span $60 \mathrm{~m}$ and rise to span ratio $(\mathrm{f} / \mathrm{L})=2 / 15$

The dome model with span $40 \mathrm{~m}$ and rise to span ratio $(\mathrm{f} / \mathrm{L})=1 / 5$ is shown in Fig. 1. Similarly dome model with span $44 \mathrm{~m}$ and rise to span ratio (f/L) $=2 / 11$, span $48 \mathrm{~m}$ and rise to span ratio $(\mathrm{f} / \mathrm{L})=1 / 6$, span $60 \mathrm{~m}$ and rise to span ratio $(\mathrm{f} / \mathrm{L})=2 / 15$ are depicted in Fig. 2, 3 and 4 respectively.

\section{Load deflection analysis}

Load deflection curves are plotted by maintaining the support as fixed and loading is provided in the form of nodal pressure loads. Load deflection curves of $60 \mathrm{~m}$ diameter dome with different spans and different rise to span ratio are shown in Fig 5.

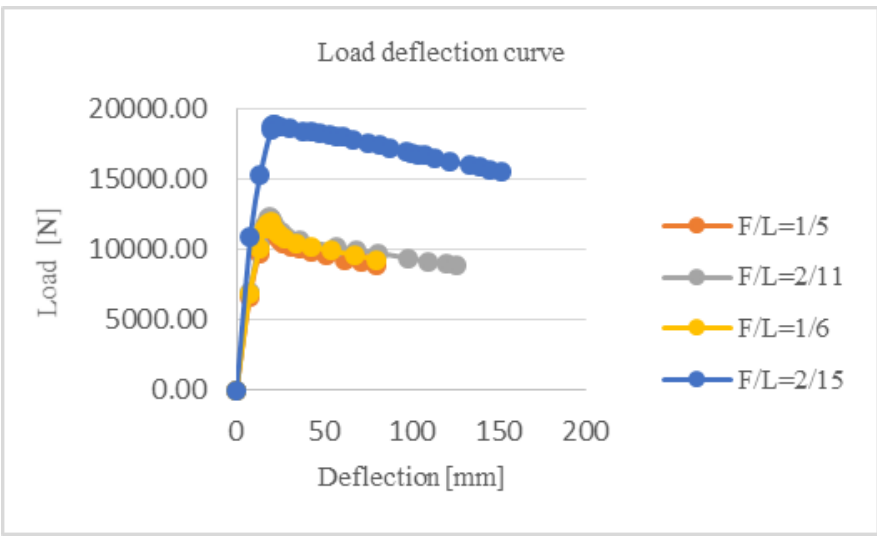

Fig. 5. Load deflection curve of $60 \mathrm{~m}$ diameter dome with different spans $(40,44,48, \& 60 \mathrm{~m})$ and different rise to span ratio (f/L)

It is observed that the dome with span $60 \mathrm{~m}$ and rise to span ratio $f / L=2 / 15$ shows maximum load carrying capacity with lower displacement value compared to other rise to span ratios $(1 / 5,2 / 11 \& 1 / 6)$. Domes with rise to span ratio $\mathrm{f} / \mathrm{L}=$ $1 / 5,2 / 11 \& 1 / 6$ of all spans shows less load carrying capacity compared to $\mathrm{f} / \mathrm{L}$ ratio as $2 / 15$. Dome with span $40 \mathrm{~m}$ and rise to span ratio $\mathrm{f} / \mathrm{L}=1 / 5$ exhibits minimum load carrying capacity.

\section{Vibration study of domes under modal analysis}

Vibration study under modal analysis and seismic performance of domes under varying rise to span ratios such as $\mathrm{f} / \mathrm{L}=1 / 5,2 / 11,1 / 6 \& 2 / 15$ were carried out. In the vibration study under modal analysis the frequencies and time 
period of domes with varying rise to span ratios such as $\mathrm{f} / \mathrm{L}=$ $1 / 5,2 / 11,1 / 6 \& 2 / 15$ are determined both in transverse and longitudinal directions. Here transverse direction is the $\mathrm{Z}$ direction and longitudinal direction is the $\mathrm{X}$ direction i.e., expanded direction.

TABLE II. FREQUENCY AND TIME PERIOD OF DOMES WITH DIFFERENT SPANS $(40,44,48 \& 60 \mathrm{M})$ AND VARYING RISE TO SPAN RATIO (F/L)

\begin{tabular}{|c|c|c|c|c|c|c|}
\hline SI No & $\begin{array}{c}\text { Span } \\
(\mathbf{m})\end{array}$ & $\begin{array}{c}\text { Rise to } \\
\text { span } \\
\text { ratios of } \\
\text { domes }\end{array}$ & \multicolumn{2}{|c|}{$\begin{array}{c}\text { Transverse } \\
\text { direction [z] }\end{array}$} & \multicolumn{2}{|c|}{$\begin{array}{c}\text { Longitudinal } \\
\text { direction [x] } \\
\text { (Expanded } \\
\text { direction) }\end{array}$} \\
\cline { 4 - 7 } & & & $\begin{array}{c}\text { Frequency } \\
\text { [f] }\end{array}$ & $\begin{array}{c}\text { Time } \\
\text { period } \\
\text { [s] }\end{array}$ & $\begin{array}{c}\text { Frequency } \\
\text { [f] }\end{array}$ & $\begin{array}{c}\text { Time } \\
\text { period } \\
\text { [s] }\end{array}$ \\
\hline 1 & 40 & $\mathrm{f} / \mathrm{L}=1 / 5$ & 12.25 & 0.0817 & 12.25 & 0.0817 \\
\hline 2 & 44 & $\mathrm{f} / \mathrm{L}=2 / 11$ & 8.89 & 0.1125 & 9.14 & 0.1095 \\
\hline 3 & 48 & $\mathrm{f} / \mathrm{L}=1 / 6$ & 5.41 & 0.1849 & 5.55 & 0.1802 \\
\hline 4 & 60 & $\mathrm{f} / \mathrm{L}=2 / 15$ & 3.20 & 0.3125 & 4.40 & 0.2273 \\
\hline
\end{tabular}

E. Seismic performance analysis of domes under transient structural

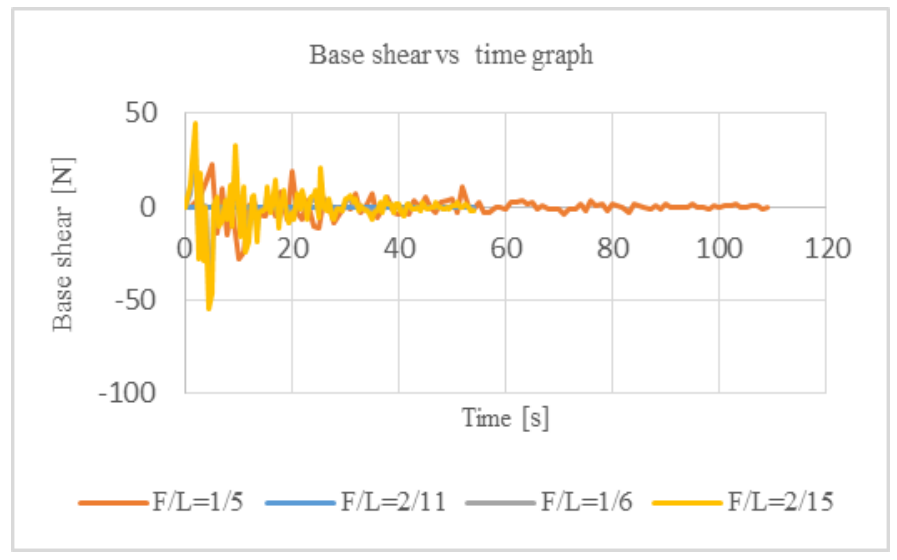

Fig. 6. Base shear vs. Time graph of domes with different spans (40, 44, 48 $\& 60 \mathrm{~m})$ and varying rise to span ratio $(\mathrm{f} / \mathrm{L})$

Seismic performance of domes were done under transient structural. Seismic performance of domes under time history analysis were done with respect to the Elcentro PGA data. The data provides the time history data file for North - south component, time (sec) and acceleration $(\mathrm{G})$. Time period (s) for the occurrence of this earthquake is take constant as 54 sec.The fig 6 , represents the variation of base shear with respect to time acting on each dome under seismic loading.

\section{RESULTS AND DISCUSSIONS}

From the load deflection analysis as shown in fig 5 , it is observed that the dome with span $=60 \mathrm{~m}$ and rise to span ratio $\mathrm{f} / \mathrm{L}=2 / 15$ shows maximum load carrying capacity with minimum displacement compared to domes with other $\mathrm{f} / \mathrm{L}$ ratios $(1 / 5,2 / 11 \& 1 / 6)$. Dome with span $=40 \mathrm{~m}$ and $\mathrm{f} / \mathrm{L}$ ratio $=1 / 5$ exhibits minimum load carrying capacity. From the vibration study under modal analysis of domes with varying $\mathrm{f} / \mathrm{L}$ values it is observed that the dome with span $=40 \mathrm{~m}$ and $\mathrm{f} / \mathrm{L}=1 / 5$ possess large frequency with minimum time period of vibration. The dome with $\operatorname{span}=60 \mathrm{~m}$ and $\mathrm{f} / \mathrm{L}=2 / 15$ possess small frequency with large time period of vibration. In the expanded $\mathrm{X}$ direction, the value of frequency is comparatively large with respect to transverse direction. From the time history analysis shown in Fig 6, it is found that the dome with span $60 \mathrm{~m}$ and $\mathrm{f} / \mathrm{L}$ ratio $=2 / 15$ possesses maximum value of shear irrespective of sign. In the analysis of whole domes maximum base shear occurs for a time interval of 0 -10sec. The whole domes possesses a steady value of base shear beyond the time $40 \mathrm{sec}$.

\section{CONCLUSIONS}

The structural performance of single axial expanded domes under seismic loading with different spans of varying rise to span ratios are analyzed and compared. The main conclusions are arrived as follows.

- From the load deflection analysis, it is found that the dome with span $60 \mathrm{~m}$ and rise to span ratio $\mathrm{f} / \mathrm{L}=2 / 15$ shows maximum load carrying capacity with minimum displacement compared to domes with other $\mathrm{f} / \mathrm{L}$ ratios $(1 / 5,2 / 11 \& 1 / 6)$. Dome with span 40 $\mathrm{m}$ and rise to span ratio $\mathrm{f} / \mathrm{L}=1 / 5$ exhibits minimum load carrying capacity.

- From the vibration study under modal analysis of domes it is found that the dome with span $40 \mathrm{~m}$ and $\mathrm{f} / \mathrm{L}=1 / 5$ possess large frequency with minimum time period of vibration. The dome with span $60 \mathrm{~m}$ and $\mathrm{f} / \mathrm{L}=2 / 15$ possess small frequency with large time period of vibration. In the expanded $\mathrm{X}$ direction, the value of frequency is comparatively large with respect to transverse direction.

- From the time history analysis (seismic) it is found that the dome with span $60 \mathrm{~m}$ and $\mathrm{f} / \mathrm{L}$ ratio $=2 / 15$ possesses maximum value of shear irrespective of sign. Base shear is an estimate of the maximum expected lateral force that will occur due to seismic ground motion at the base of a structure. In the analysis of all types of domes, maximum base shear occurs for a time interval of $0-10 \mathrm{sec}$. They also possess a steady value of base shear beyond the time $40 \mathrm{sec}$

\section{REFERENCES}

[1] De-Min Wei et.al (2017) "Seismic response analysis of K8 pattern single-layer reticulated domes under vertical rare earthquakes" Procedia Engineering,vol. 210, pp. 417-424.

[2] Qingwen Zhang et.al (2017) "Finite element analysis of the static properties and stability of a $800 \mathrm{~m}$ Kiewit type mega-latticed structure" Journal of Constructional Steel Research,vol. 137 ,pp. 201-210.

[3] Gui-bo Nie et.al (2014) "Seismic performance evaluation of singlelayer reticulated dome and its fragility analysis" Journal of Constructional Steel Research, vol. 100, pp. 176-182.

[4] Yongjun He et.al (2014) "Seismic performance of cylindrical latticedintersected-three-dimensional-beam-system reticulated mega-structure with single-layer latticed-intersected-cylindrical-shell substructures" Soil Dynamics and Earthquake Engineering ,vol. 57 ,pp.15-24. 